\title{
Correlation Between Cognitive Function Impairment and Chronic Kidney Disease With a Low Glomerular Filtration Rate at Sanglah Hospital Denpasar
}

\author{
Anak Agung Ayu Putri Laksmidewi ${ }^{1 *}$, Cok Istri Gangga Dewi ${ }^{1}$, Yenny Kandarini $^{2}$ \\ ${ }^{1}$ Department of Neurology, Faculty of Medicine, Udayana University, Sanglah General Hospital, Bali, Indonesia; ${ }^{2}$ Department \\ of Internal Medicine, Division of Nephrology/Hypertension, Faculty of Medicine, Udayana University, Sanglah General Hospital, \\ Bali, Indonesia
}

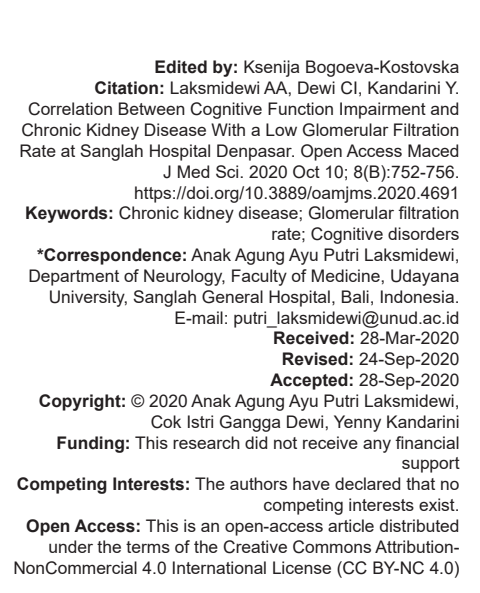

\begin{abstract}
BACKGROUND: Chronic kidney disease is a condition of chronic kidney damage with abnormal structure and function of the kidneys that lasts more than 3 months, accompanied or not by a decrease in glomerular filtration rate. Organic kidney disease leaves accumulated organic waste that cannot be removed by the kidneys. Furthermore, several biochemical and metabolic mechanisms such as chronic inflammation and oxidative stress can cause executive disorders.

AIM: The aim of the study was to find out an increased risk of impaired cognitive function in patients with chronic kidney disease with a low glomerular filtration rate in Sanglah Hospital.

METHOD: This study uses a retrospective case-control analytic observational study design. We included all patients with chronic kidney disease in Sanglah Hospital in December 2017-January 2018. This study involved 46 subjects with chronic kidney disease who met eligibility criteria, classified as a case group with cognitive impairment and a control group without cognitive impairment.

RESULTS: Each decrease in glomerular filtration rate $<30 \mathrm{ml} / \mathrm{min} / 173 \mathrm{~m}^{2}$ in patients with chronic renal failure correlates with an increased incidence of cognitive impairment of around $15-25 \%$. The risk of chronic kidney disease patients with glomerular filtration rate $<30 \mathrm{ml} / \mathrm{min} / 1.73 \mathrm{~m}^{2}$ decreased cognitive function 13 times compared to subjects with glomerular filtration rate $>30 \mathrm{ml} / \mathrm{min} / 1.73 \mathrm{~m}^{2}$.
\end{abstract}

CONCLUSION: Low glomerular filtration rate correlate with increased risk of cognitive impairment.

\section{Introduction}

Chronic kidney disease is chronic damage to kidney due to abnormalities in both structure and function of the kidney with or without a decrease in glomerular filtration rate that occurs more than 3 months. Disorders in the field of neurology such as cognitive impairment, disequilibrium syndrome, or uremic encephalopathy occur in chronic kidney disorders with a low glomerular filtration rate of $<50 \%$.

Cognition is a process of being able to receive sensory input, remember an event, make generalizations, give analogies, explain, and communicate. Cognitive disorders are disturbances in rational thought processes including, interruptions in the process of receiving information, processing, storing, and remembering until releasing that information.

Arcienegas et al. (2013) divide cognitive into basic and complex. Basic cognitive consists of arousal, attention, memory, praxis, and recognition while cognitive complex consists of executive functions, social intelligence, and motivation [1].

Impaired cognitive function in chronic kidney disease is often overlooked and not observed by clinicians. Impairment of cognitive function here is caused by metabolic and biochemical mechanisms in the central nervous system in the form of oxidative stress, chronic inflammatory reactions, anemia, hyperhomocysteinemia, vascular problems, endothelial dysfunction, as well as uremic toxins.[2], [3] The previous studies have reported that patients with chronic kidney disease have twice the risk of experiencing cognitive impairment compared to healthy people and 4 times more often experience cognitive impairment when the glomerular filtration rate decreases to $<30 \mathrm{ml} / \mathrm{min} / 1.73 \mathrm{~m}^{2}$. Each reduction in glomerular filtration rate of $10 \mathrm{ml} / \mathrm{min} / 173 \mathrm{~m}^{2}$ in patients with chronic renal failure correlates with an increase in the incidence of impaired cognitive function around $15-25 \%$ and this cognitive problem can occur earlier 3.6-7 years [4]. Executive function 
is one of the domains of cognitive function that is quite common. The executive function is a cognitive function with a complex process of initiating responses, adjusting behavior, knowing mistakes, forming motor movements, and making a decision. A meta-analysis study reported a significant relationship between increased risk of cognitive impairment in patients with chronic kidney disease, especially mild and moderate degrees and glomerular filtration rates of $45-60 \mathrm{ml} / \mathrm{min} / 1.73 \mathrm{~m}^{2}$ [2]. Each decrease in glomerular filtration rate $<30 \mathrm{ml} / \mathrm{min} / 1.73 \mathrm{~m}^{2}$ in patients with chronic renal failure correlates with an increased incidence of cognitive impairment of around $15-25 \%$.

\section{Methods}

This study is an observational analytic study with a case-control design to determine whether the low glomerular filtration rate increases the risk of cognitive impairment in patients with chronic kidney disease, taking place in Neurology and Internal Medicine Outpatient Clinic at Sanglah General Hospital in December 2017-January 2018. Based on the previous studies, we implement the cutoff of low glomerular filtration rate as $<30 \mathrm{ml} / \mathrm{min} / 1.73 \mathrm{~m}^{2}$. The inclusion criteria for case group were as follows: (1) Patient with chronic kidney disease based on glomerular filtration rate $<100 \mathrm{ml} / \mathrm{min} / 1.73 \mathrm{~m}^{2}$ or $\geq 15 \mathrm{ml} / \mathrm{min} / 1.73 \mathrm{~m}^{2}$, (2) chronic kidney disease with cognitive impairment, and (3) 40-70 years old. Control group inclusion criteria are the same with case group but they should not have any cognitive impairment. Exclusion criteria for both case and control group: (1) Hemoglobin $<6 \mathrm{mg} / \mathrm{dL}$, (2) history of liver disease, critical illness, malignancy, and (3) immunity disorder such as SLE, AIDS, or other disease that can affect the cognitive function.

Impaired cognitive function was assessed with an MoCA-Ina (Montreal Cognitive AssessmentIndonesian) instrument. The total MoCA-Ina value was 30 with a cutoff of $<26$ indicating impaired cognitive function. Adjustments to the MoCA-Ina for low levels of education must add 2 points to the total value for 4-9 years of formal education, and 1 point for $10-12$ years of formal education.

The data that have been obtained are processed either using Statistical Product and Service Solution (SPSS) program version 20.0. Data analysis is carried out in two stages, descriptive, and analytic statistical stages. Descriptive statistics are used to see an overview of the basic characteristics of research subjects. The statistic analysis was performed by ChiSquare test. The level of significance was expressed as $p<0.05$ with a $95 \%$ confidence interval.

\section{Results}

This study involved 46 subjects with chronic kidney disease who met the eligibility criteria, classified as a group of cases with cognitive impairment and control groups, without cognitive impairment. Characteristics of research subjects are presented in Table 1.

Table 1: Characteristics of research subjects

\begin{tabular}{|c|c|c|c|}
\hline Variables & $\begin{array}{l}\text { Case MoCA-Ina }<26 \\
\mathrm{n}(\%)\end{array}$ & $\begin{array}{l}\text { Control MoCA-Ina }>26 \\
\mathrm{n}(\%)\end{array}$ & $p$-value \\
\hline \multicolumn{4}{|l|}{ Gender } \\
\hline Males & $7(30.4 \%)$ & $13(56.5 \%)$ & 0.074 \\
\hline Females & $16(69.6 \%)$ & $10(43.5 \%)$ & \\
\hline \multicolumn{4}{|l|}{ Age } \\
\hline$<60$ years & $18(78.3 \%)$ & $20(87 \%)$ & 0.437 \\
\hline$>60$ years & $5(21.7 \%)$ & $3(13 \%)$ & \\
\hline \multicolumn{4}{|l|}{ Education } \\
\hline$<12$ years & 18 (78.3\%) & $7(30.4 \%)$ & 0.001 \\
\hline$>12$ years & $5(21.7 \%)$ & $16(69.6 \%)$ & \\
\hline Occupation & & & 0.017 \\
\hline Informal & $17(73.9 \%)$ & $9(39.1 \%)$ & \\
\hline Formal & $6(26.1 \%)$ & $14(60.9 \%)$ & \\
\hline
\end{tabular}

In Table 1, the case group with cognitive impairment found seven male subjects (30.4\%) and 16 female subjects $(69.6 \%)$. In the control group without cognitive impairment, there were 13 male subjects $(56.5 \%)$ and ten female subjects $(43.5 \%)$, with $p=0.074$ which means that there were no significant differences in the sex variables.

There are 18 people $(78.3 \% ;<60$ years) and five elderly $(21.7 \% ; \geq 60$ years) in the case group. In the control group, there are 20 people $(87 \% ;<60$ years) and three elderly $(13 \% ; \geq 60$ years), with $p=0.437$, which means there were no significant differences in the age variable in both case and control groups.

In this study, the case group found the education $<12$ years by 18 people $(78.3 \%)$ and education $>12$ years by five people $(21.7 \%)$. In the control group, it was found that the education $<12$ years was seven people $(30.4 \%)$, while education $>12$ years was 16 people $(69.6 \%)$, with $p=0.001$ which means that there were significant differences in the education variable.

In the occupational variable, the case group found subjects with 17 informal occupations $(73.9 \%)$ and six with formal occupations $(26.1 \%)$. In the control group, there were subjects with nine informal occupations (39.1\%) and 14 with formal occupations $(22.9 \%)$, with $p=0.017$ which means that there were significant differences in the types of occupation variables.

The correlation between glomerular filtration rate and cognitive function using MoCA-Ina is described in Table 2. Seventeen patient with impaired cognitive

Table 2: The correlation between glomerular filtration rate and cognitive function using MoCA-Ina

\begin{tabular}{|c|c|c|c|c|c|}
\hline \multirow[t]{2}{*}{ Variable } & & \multicolumn{2}{|c|}{$\begin{array}{l}\text { Cognitive impairment } \\
\text { MOCA-Ina }\end{array}$} & \multirow[t]{2}{*}{$\begin{array}{l}\text { OR } \\
(95 \% \mathrm{Cl})\end{array}$} & \multirow[t]{2}{*}{$p$-value } \\
\hline & & Yes n (\%) & No $\mathrm{n}(\%)$ & & \\
\hline $\begin{array}{l}\text { Glomerular filtration rate } \\
\left(\mathrm{ml} / \mathrm{min} / 1,73 \mathrm{~m}^{2}\right)\end{array}$ & $\begin{array}{l}<30 \\
>30 \\
\end{array}$ & $\begin{array}{l}17(73.9 \%) \\
6(26.1 \%) \\
\end{array}$ & $\begin{array}{l}4(17.4 \%) \\
19(82.6 \%)\end{array}$ & $\begin{array}{l}13,45 \\
(3.23-55.92) \\
\end{array}$ & $<0.001^{*}$ \\
\hline
\end{tabular}


function was found in low glomerular filtration rate patient $<30 \mathrm{ml} / \mathrm{min} / 1.73 \mathrm{~m}^{2}(73.9 \%)$, while in the control group with glomerular filtration rate $>30 \mathrm{ml} / \mathrm{min} / 1.73 \mathrm{~m}^{2}$ only six patient $(26.1 \%)$. There is a significant difference in the occurrence of cognitive impairment in patients with chronic kidney disease with a glomerular filtration rate $<30 \mathrm{ml} / \mathrm{min} / 1.73 \mathrm{~m}^{2}$ compared to patients with chronic kidney disease with a glomerular filtration rate $>30 \mathrm{ml} /$ $\mathrm{min} / 1.73 \mathrm{~m}^{2}$ with an OR $13.45,95 \% \mathrm{Cl} 3.23-55.92$ and $p<0.001$. The risk of chronic kidney disease with a glomerular filtration rate $<30 \mathrm{ml} / \mathrm{min} / 1.73 \mathrm{~m}^{2}$ decreased cognitive function is 13 times compared to subjects with glomerular filtration rate $>30 \mathrm{ml} / \mathrm{min} / 1.73 \mathrm{~m}^{2}$ which is statistically significant.

Other factors such as anemia, high blood pressure, diabetes mellitus, and hemodialysis also play a role in causing cognitive dysfunction. The relationship of other factors as a cause of cognitive decline was analyzed using the Chi-square test and Fisher's Exact. The analysis results are presented in Table 3.

Table 3: The other factors correlated to decrease cognitive function

\begin{tabular}{|c|c|c|c|c|}
\hline \multirow[t]{2}{*}{ Variables } & \multicolumn{2}{|c|}{ Cognitive impairment } & \multirow{2}{*}{ OR $(95 \% \mathrm{Cl})$} & \multirow{2}{*}{$p$-value } \\
\hline & Yes n (\%) & No n (\%) & & \\
\hline \multicolumn{5}{|c|}{ Diabetes mellitus } \\
\hline Yes & $6(26.1)$ & $5(21.7)$ & $1.27(0.03-4.94)$ & 0.5 \\
\hline No & $17(73.9)$ & $18(78.3)$ & & \\
\hline \multicolumn{5}{|l|}{ Hypertension } \\
\hline Yes & $15(65.2)$ & $17(73.9)$ & $0.66(0.18-2.34)$ & 0.37 \\
\hline No & $8(34.8)$ & $6(26.1)$ & & \\
\hline \multicolumn{5}{|l|}{ Anemia } \\
\hline Yes & $21(91.3)$ & $20(87.0)$ & $0.5(0.23-10.43)$ & 0.63 \\
\hline No & $2(8.7)$ & $3(13.0)$ & & \\
\hline Hemodialysis & & & & 0.03 \\
\hline Yes & $13(56.5)$ & $6(26.1)$ & $3.683(1.06-12.77)$ & \\
\hline No & $10(43.5)$ & $17(73.9)$ & & \\
\hline
\end{tabular}

Impaired cognitive function in subjects with diabetes mellitus was $26.1 \%$, while in subjects without diabetes mellitus it was $73.9 \%$. The relationship between diabetes mellitus and decreased cognitive function was analyzed using the Chi-square test and obtained OR $1.27,95 \% \mathrm{Cl} 0.03-4.94, \mathrm{p}=0.5$ which means that statistically there was no significant relationship between diabetes mellitus and cognitive function decline.

The incidence of cognitive decline in subjects with high blood pressure was $65.2 \%$ and in subjects who were not with high blood pressure were $34.8 \%$. The relationship between high blood pressure and decreased cognitive function was analyzed using the Chi-square test and OR $0.66,95 \% \mathrm{Cl} 0.18-2.34$, $p=0.37$ which means that statistically there was no significant relationship between blood pressure and cognitive function decline.

The decrease in cognitive function in subjects with anemia was $91.3 \%$ and in subjects without anemia it was $8.7 \%$. The relationship between anemia and decreased cognitive function was analyzed using Fisher's exact test and obtained OR $0.5,95 \% \mathrm{Cl} 0.23-$ 10.47, $p=0.63$, which means that statistically there was no significant relationship between anemia and cognitive decline.
The incidence of cognitive decline in subjects with hemodialysis was $56.5 \%$ and in subjects without hemodialysis was $43.5 \%$. The relationship between hemodialysis and cognitive decline was analyzed using the Chi-square test and obtained OR 3.68, 95\% Cl 1.06-12.77, $p=0.03$ which means that statistically there is a significant relationship between hemodialysis and decreased cognitive function.

\section{Discussion}

This study showed that the risk of experiencing cognitive impairment in patients with chronic kidney disease in subjects with a glomerular filtration rate $<30 \mathrm{ml} / \mathrm{min} / 1.73 \mathrm{~m}^{2}$ is 13 times compared to subjects with glomerular filtration rate values $>30 \mathrm{ml} / \mathrm{min} / 1.73 \mathrm{~m}^{2}$ where this result is statistically significant. The same thing is in line with research conducted by Bronas et al. (2017), the risk increases to 4 times when the glomerular filtration rate decreases to $<30 \mathrm{ml} / \mathrm{min} / 1.73 \mathrm{~m}^{2}$ [4]. Patients with chronic kidney disease can experience impaired cognitive function more quickly 3.6-7 years compared to normal individuals. Another study by Bugnicourt et al. (2013) found that patients with chronic kidney disease with glomerular filtration rate $<30 \mathrm{ml} / \mathrm{min} / 1.73 \mathrm{~m}^{2}$ are more often experience cognitive impairment in all domains of attention, language, visuospatial, memory, and function executive [5]. In another cross-sectional study by Buchman et al. (2009), kidney disease patients with low glomerular filtration rates experienced faster cognitive impairment [6]. It is said that chronic stage kidney disease is associated with an increased risk of dementia of about $37 \%$. In another study by Kurrela et al. (2004) in 80 participants they obtained a prevalence of impaired cognitive function around $23-28 \%$ in chronic kidney disease Stage 3 to Stage 4 [4], [5], [7].

The kidneys and brain have similarities in anatomy and vasoregulatory features where it has low vascular resistance that can ease vascular injury. The prevalence of traditional vascular risk factors such as arterial hypertension is higher in patients with chronic kidney disease than in the general population. The presence of vascular abnormalities tends to cause cognitive impairment compared to Alzheimer's dementia in patients with chronic kidney disease. The study of Helmer et al. (2011) was found that a decrease in kidney function by $>4 \mathrm{ml} / \mathrm{min} / 1.73 \mathrm{~m}^{2}$ for 4 years is associated with a decrease in overall cognitive function and vascular dementia [8]. More often there are cognitive function disorders in the domain of executive function, but memory function and other domains can also occur [2], [5].

An increase in cognitive decline in kidney disease patients is related to various factors, either due 
to metabolic disorders such as uremic, oxidative stress, or due to vascular endothelial dysfunction. The presence of these factors causes vascular dysfunction associated with disorders of white matter and neurodegenerative damage associated with uremic toxins, homocysteine, creatinine, and cystatin C [4], [9].

In a previous study, in 336 study subjects obtained low scores on cognitive screening using MMSE in patients with chronic kidney disease by hemodialysis. The existence of a low cognitive screening value is related to mortality rates and length of hospital stay in patients with chronic kidney disease [10].

Another study, namely, Kurrela, et al. (2006) in 16.694 research subjects with hemodialysis found a correlation between dialysis and dementia [11]. In subjects with hemodialysis with impaired cognitive function such as dementia, the risk of death was higher (RR 1.48, 95\% Cl 1.32-1.66). The presence of uremic factors is associated with cognitive impairment in patients with chronic kidney disease by dialysis [11], [12].

In this study, we found no significant relationship between high blood pressure and cognitive impairment. This is in contrast to research conducted by ladecola et al. in 2016 in patients with high blood pressure, it was found that hypertension is associated with the occurrence of cognitive dysfunction in the long term [13]. In another study, by Pase et al. in 2016 in a cohort study it was found that aortic thickening as a predictor of the occurrence of both mild and dementia cognitive impairment in non-diabetic patients followed for 10 years [14]. Other study conducted by Khatri et al. (2009) with a cohort design on 3.029 research subjects with chronic kidney disease, at a glomerular filtration rate $<60 \mathrm{ml} / \mathrm{min} / 1.73 \mathrm{~m}^{2}$ obtained $74 \%$ with high blood pressure and $86 \%$ in this group with cognitive impairment with $p<0.001$ [15].

Various research studies have examined the relationship between diabetes mellitus and cognitive impairment. In the study of Spauwen et al. (2013) with a prospective cohort design for 12 years, it was found that individuals with diabetes mellitus had a tendency to experience cognitive dysfunction, especially in processing speed and executive function compared to normal individuals [16]. Roberts, et al. (2013) examined the relationship of diabetes with memory disorders with a prospective 5-year design that diabetes increased the risk of mild cognitive impairment with OR $1.39,95 \% \mathrm{Cl}$ 1.08-1.79 [17].

In contrast to the study conducted by MacKnight, et al. (2002) who examined the relationship of diabetes with Alzheimer's and vascular cognitive impairment with a prospective cohort design of 5 years, the results showed no relationship between diabetes and the incidence of Alzheimer's dementia, RR 0.87 , $95 \% \mathrm{Cl} 0.34-2.21$ [18]. In addition, in a study conducted by Paraizo et al. (2015), there were also no significant results of cognitive impairment with high blood pressure in the case and control groups with a value of $p=0.06$. In this study, the results were not meaningful because the number of subjects with diabetes mellitus was almost the same in the case and control groups. In addition, the effects of the duration of suffering from diabetes, as well as the use of diabetes drugs such as insulin were not analyzed in this study [19].

A positive correlation of anemia with impaired cognitive function was found in two recent studies in 2013, namely, The Health ABC Study conducted by Hong, et al. a study to determine the relationship of anemia and risk of dementia with a cohort design in which patient development was followed for 11 years [20]. The results show that anemia is associated with an increased risk of dementia which is $23 \%$ compared to $17 \%$, with a risk of dementia of 1.6 times compared to normal people. The second study, in a systematic review design, has the same goal states that there is a possible relationship between anemia and cognitive impairment, especially executive function, and if cognitive impairment has occurred because of anemia, anemia correction must be sought to reach the normal level of hemoglobin. In another study, Antunes et al. (2011) in 214 elderly study subjects with renal impairment, the results obtained were around 54.5\% anemia research subjects with glomerular filtration rate $<60 \mathrm{ml} / \mathrm{min} / 1.73 \mathrm{~m}^{2}$ compared to research subjects with glomerular filtration rate $>90 \mathrm{ml} / \mathrm{min} / 1.73 \mathrm{~m}^{2}$ with $p<0.001$ [21].

Studies that were negatively correlated among others were found in studies from Atkinson, et al. (2005) which stated that hemoglobin levels were not significantly associated with decreased cognitive function with OR $0.86,95 \% \mathrm{Cl} 0.60-1.21$ [22]. A study from Shah et al. (2011) also found that cognitive impairment could occur not only in anemia but also in the increased hemoglobin state (polycythemia) [23]. In this study, the results were not meaningful because the number of samples in the case and control groups was almost the same. In the study included in the inclusion criteria were patients with anemia with hemoglobin $>6$ (mild-moderate anemia) while those with severe anemia were excluded. In addition, there was no analysis of the duration of anemia and a history of treatment that affected the quality of life of patients with anemia in chronic kidney disease.

\section{Conclusion}

Conclusions from the results of this study are an increase in the risk of impaired cognitive function by 13 times which is statistically significant in patients with chronic kidney disease with a low glomerular filtration rate at the Sanglah General Hospital. 


\section{References}

1. Arciniegas DB, Anderson CA, Filley CM. Structural and functional neuroanatomy executive function. In: Behavioral Neurology and Neuropsychiatry. England: Cambridge University Press; 2013. https://doi.org/10.1017/cbo9781139016919.018

2. Etgen T. Kidney disease as a determinant of cognitive decline and dementia. Alzheimers Res Ther. 2015;7(1):29. https://doi. org/10.1186/s13195-015-0115-4

PMid:25780391

3. da Matta SM, Moreira JM, E Kummer AM, Guimarães I, Teixeira AL, E Silva AC. Cognitive alterations in chronic kidney disease: An update. J Bras Nefrol. 2014;36(2):241-5. PMid:25055365

4. Bronas UG, Puzantian H, Hannan M. Cognitive impairment in chronic kidney disease: Vascular milieu and the potential therapeutic role of exercise. Biomed Res Int. 2017;2017:2726369. https://doi.org/10.1155/2017/2726369

PMid:28503567

5. Bugnicourt JM, Godefroy O, Chillon JM, Choukroun G, Massy ZA. Cognitive disorders and dementia in CKD: The neglected kidney-brain axis. J Am Soc Nephrol. 2013;24(3):35363. https://doi.org/10.1681/asn.2012050536

\section{PMid:23291474}

6. Buchman AS, Tanne D, Boyle PA, Shah RC, Leurgans SE, Bennett DA. Kidney function is associated with the rate of cognitive decline in the elderly. Neurology. 2009;73(12):920-7. https://doi.org/10.1212/wnl.0b013e3181b72629

PMid:19657107

7. Kurella M, Chertow GM, Luan J, Yaffe K. Cognitive impairment in chronic kidney disease. J Am Geriatr Soc. 2004;52(11):18639. https://doi.org/10.1111/j.1532-5415.2004.52508.x PMid: 15507063

8. Helmer C, Stengel B, Metzger M, Froissart M, Massy ZA Tzourio $\mathrm{C}$, et al. Chronic kidney disease, cognitive decline, and incident dementia: The 3C Study. Neurology. 2011;77(23):204351. https://doi.org/10.1212/wnl.0b013e31823b4765 PMid:22116945

9. De Deyn PP, Vanholder R, Eloot S, Glorieux G. Progress in uremic toxin research: Guanidino compounds as uremic (neuro) toxins. In: Seminars in Dialysis. United States: Wiley; 2009. p. 340-5. https://doi.org/10.1111/j.1525-139x.2009.00577.x

10. Patel M, Dasgupta I, Tadros G, Baharani J. Cognitive impairment in hemodialysis patients: What can slow this decline? Hong Kong J Nephrol. 2016;18:4-10. https://doi.org/10.1016/j. hkjn.2015.08.003

11. Kurella M, Mapes DL, Port FK, Chertow GM. Correlates and outcomes of dementia among dialysis patients: The dialysis outcomes and practice patterns study. Nephrol Dial Transplant. 2006;21(9):2543-8. https://doi.org/10.1093/ndt/gfl275 PMid:16751655

12. Grimm G, Stockenhuber F, Schneeweiss B, Madl C, Zeitlhofer J, Schneider B. Improvement of brain function in hemodialysis patients treated with erythropoietin. Kidney Int.
1990;38(3):480-6. https://doi.org/10.1038/ki.1990.229 PMid:2232491

13. ladecola C, Yaffe K, Biller J, Bratzke LC, Faraci FM, Gorelick PB, et al. Impact of hypertension on cognitive function: A scientific statement from the American heart association. Hypertension. 2016;68(6):e67-94. https://doi.org/10.1161/ hyp.0000000000000053

14. Pase MP, Beiser A, Himali JJ, Tsao C, Satizabal CL, Vasan RS, et al. Aortic stiffness and the risk of incident mild cognitive impairment and dementia. Stroke. 2016;47(9):2256-61. https:// doi.org/10.1161/strokeaha.116.013508

PMid:27491735

15. Khatri M, Nickolas T, Moon YP, Paik MC, Rundek T, Elkind MS et al. CKD associates with cognitive decline. J Am Soc Nephrol. 2009;20(11):2427-32. https://doi.org/10.1681/asn.2008101090 PMid: 19729443

16. Spauwen PJ, Köhler S, Verhey FR, Stehouwer CD, van Boxtel MP. Effects of Type 2 diabetes on 12-year cognitive change: Results from the Maastricht aging study. Diabetes Care. 2013;36(6):1554-61. https://doi.org/10.2337/dc12-0746 PMid:23275366

17. Roberts R, Knopman DS. Classification and epidemiology of $\mathrm{MCl}$. Clin Geriatr Med. 2013;29(4):753-72. PMid:24094295

18. MacKnight C, Rockwood K, Awalt E, McDowell I. Diabetes mellitus and the risk of dementia, Alzheimer's disease and vascular cognitive impairment in the Canadian study of health and aging. Dement Geriatr Cogn Disord. 2002;14(2):77-83. https://doi.org/10.1159/000064928 PMid:12145454

19. de Andrade Paraizo M, Almeida AL, Pires LA, Abrita RS, Crivellari MH, Dos Santos Pereira B, et al. Montreal cognitive assessment (MoCA) screening mild cognitive impairment in patients with chronic kidney disease (CKD) pre-dialysis. Braz J Nephrol. 2016;38(1):31-41. https://doi. org/10.5935/0101-2800.20160006 PMid:27049362

20. Hong $\mathrm{CH}$, Falvey C, Harris TB, Simonsick EM, Satterfield S, Ferrucci L, et al. Anemia and risk of dementia in older adults: Findings from the health ABC study. Neurology. 2013;81(6):52833. https://doi.org/10.1212/wnl.0b013e31829e701d PMid:23902706

21. Antunes JP, Bulhões C, Fonte P, Abreu MJ, Oliveira R. Renal function and cognitive dysfunction: Cross-sectional study of users enrolled at ponte-family health unit. Braz J Nephrol. 2015;37(1):79-90. https://doi.org/10.5935/0101-2800.20150012

22. Atkinson $\mathrm{HH}$, Cesari M, Kritchevsky SB, Penninx BW, Fried LP, Guralnik JM, et al. Predictors of combined cognitive and physical decline. J Am Geriatr Soc. 2005;53(7):1197-202. https://doi. org/10.1111/j.1532-5415.2005.53362.x PMid: 16108938

23. Shah RC, Buchman AS, Wilson RS, Leurgans SE, Bennett DA. Hemoglobin level in older persons and incident Alzheimer disease:Prospective cohortanalysis. Neurology. 2011;77(3):21926. https://doi.org/10.1212/wnl.0b013e318225aaa9 PMid:21753176 